Joost Wauters

Katrien Lagrou

Alexander Wilmer

Philippe Jorens

Greet Hermans

\section{Invasive pulmonary aspergillosis in the ICU: reply to Wichmann et al.}

Accepted: 20 December 2012

Published online: 22 January 2013

(C) Springer-Verlag Berlin Heidelberg and ESICM 2013

This reply refers to the comment available at: doi:10.1007/s00134-012-2809-4.

Dear Editor,

We thank Dr. Wichmann and colleagues for their interesting remarks and discussion on our study [1] and we aim to further clarify their concerns.

Although the diagnosis of invasive pulmonary aspergillosis (IPA) was made before or on the day of ICU admission in three of the five proven IPA patients, IPA diagnosis was made a median of 2 days after H1N1 diagnosis, as stated in the "Results" section of the paper. In none of the nine IPA patients (5 proven, 4 probable) was the diagnosis of IPA established before the diagnosis of H1N1. Moreover, respiratory symptoms, myalgia and fever were present before formal H1N1 diagnosis based on the respiratory sample taken at hospital or ICU admission, suggesting a delay in H1N1 diagnosis. We do acknowledge that the retrospective character of the study does not allow one to confirm a causal relationship and our findings have to be confirmed in larger prospective studies. On the other hand, the incidence of IPA in solid organ transplant patients is known to be about $0.5 \%$ for kidney and up to $12 \%$ for lung transplants [2-4]. The higher incidence (23\%) found in our study again may suggest that IPA is probably a true H1N1related superinfection on top of the existing risk for fungal infection associated with a solid organ transplant.

We appreciate Wichmann et al.'s concern that some of the probable IPA cases were merely colonization. The clinical condition of critically ill patients, however, often does not allow invasive diagnostic procedures. However, even if only taking into account the five proven IPA cases, H1N1-related IPA incidence still was much higher than the 1.6-1.8\% reported so far in current literature $[5,6]$.

\section{References}

1. Wauters J, Baar I, Meersseman P, Meersseman W, Dams K, De Paep R, Lagrou K, Wilmer A, Jorens P, Hermans G (2012) Invasive pulmonary aspergillosis is a frequent complication of critically ill $\mathrm{H} 1 \mathrm{~N} 1$ patients: a retrospective study. Intensive Care Med 38:1761-1768. doi:10.1007/s00134012-2673-2

2. Gavalda J, Len O, San Juan R, Aguado JM, Fortun J, Lumbreras C, Moreno A, Munoz P, Blanes M, Ramos A, Rufi G, Gurgui M, Torre-Cisneros J, Montejo M, Cuenca-Estrella M, Rodriguez-Tudela JL, Pahissa A, RESITRA (Spanish Network for Research on Infection in Transplantation) (2005) Risk factors for invasive aspergillosis in solid-organ transplant recipients: a case-control study. Clin Infect Dis 41:52-59

3. Minari A, Husni R, Avery RK, Longworth DL, DeCamp M, Bertin M, Schilz R, Smedira N, Haug MT, Mehta A, Gordon SM (2002) The incidence of invasive aspergillosis among solid organ transplant recipients and implications for prophylaxis in lung transplants. Transpl Infect Dis 4:195-200
4. Pappas PG, Alexander BD, Andes DR, Hadley S, Kauffman CA, Freifeld A, Anaissie EJ, Brumble LM, Herwaldt L, Ito J, Kontoyiannis DP, Lyon GM, Marr KA, Morrison VA, Park BJ, Patterson TF, Perl TM, Oster RA, Schuster MG, Walker R, Walsh TJ, Wannemuehler KA, Chiller TM (2010) Invasive fungal infections among organ transplant recipients: results of the TransplantAssociated Infection Surveillance Network (TRANSNET). Clin Infect Dis 50:1101-1111

5. Kim SH, Hong SB, Yun SC, Choi WI, Ahn JJ, Lee YJ, Lee HB, Lim CM, Koh Y, Korean Society of Critical Care Medicine H1N1 Collaborative (2011) Corticosteroid treatment in critically ill patients with pandemic influenza A/H1N1 2009 infection: analytic strategy using propensity scores. Am J Respir Crit Care Med 183:1207-1214

6. Martin-Loeches I, Lisboa T, Rhodes A, Moreno RP, Silva E, Sprung C, Chiche JD, Barahona D, Villabon M, Balasini C, Pearse RM, Matos R, Rello J, ESICM H1N1 Registry Contributors (2011) Use of early corticosteroid therapy on ICU admission in patients affected by severe pandemic $(\mathrm{H} 1 \mathrm{~N} 1) \mathrm{v}$ influenza A infection. Intensive Care Med 37:272-283

J. Wauters ( $)$ A. Wilmer - G. Hermans Medical Intensive Care Unit, University Hospitals Leuven, 3000 Leuven, Belgium e-mail: joost.wauters@med.kuleuven.be Tel.: +32-16-344275

Fax: +32-16-344230

K. Lagrou

Laboratory Medicine, University Hospitals Leuven, 3000 Leuven, Belgium

P. Jorens

Intensive Care Unit, Antwerp University Hospital, 2650 Edegem, Belgium 